\title{
Low-Cyclic Loading Tests of Self-Centering Variable Friction (SCVF) Brace
}

\author{
Qingguang He $\mathbb{D}^{1},{ }^{1}$ Yanxia Bai $\mathbb{D},{ }^{1}$ Weike $W u\left(D,{ }^{2}\right.$ and Yongfeng $D u^{1}$ \\ ${ }^{1}$ Key Laboratory of Disaster Prevention and Mitigation in Civil Engineering of Gansu Province, \\ Lanzhou University of Technology, Lanzhou, China \\ ${ }^{2}$ Foshan Railway Investment Construction Group Co., Ltd., Foshan, China \\ Correspondence should be addressed to Qingguang He; heqingguang@lut.edu.cn
}

Received 10 June 2020; Revised 18 October 2020; Accepted 5 November 2020; Published 17 November 2020

Academic Editor: Wahyu Caesarendra

Copyright (c) 2020 Qingguang He et al. This is an open access article distributed under the Creative Commons Attribution License, which permits unrestricted use, distribution, and reproduction in any medium, provided the original work is properly cited.

\begin{abstract}
A novel assembled self-centering variable friction (SCVF) brace is proposed which is composed of an energy dissipation system, a self-centering system, and a set of force transmission devices. The hysteretic characteristics and energy dissipation of the SCVF brace with various parameters from low-cyclic loading tests are presented. A finite element model was constructed and tested under simulated examination for comparative analysis. The results indicate that the brace shows an atypical flag-type hysteresis curve. The SCVF brace showed its stable self-centering ability and dissipation energy capacity within the permitted axial deformation under different spring and friction plates. A larger deflection of the friction plate will make the variable friction of this SCVF brace more obvious. A higher friction coefficient will make the energy dissipation capacity of the SCVF brace stronger, but the actual friction coefficient will be lower than the design value after repeated cycles. The results of the fatigue tests showed that the energy dissipation system formed by the ceramic fiber friction blocks and the friction steel plates in the SCVF brace has a certain stability. The finite element simulation results are essentially consistent with the obtained test results, which is conducive to the use of finite element software for calculation and structural analysis in actual engineering design.
\end{abstract}

\section{Introduction}

Conventional brace (CB) [1] and buckling restrained braces (BRB) [2] which are two kinds of damper elements are usually introduced in moment-resisting steel frames. The former has superior axial stiffness, which can improve the lateral stiffness of the structure and mitigate the interstory displacement response of the structure under low- and medium-level earthquakes. Not only does the latter have the advantage of the former but also its stable plastic deformation ability can make the structure have effective energy dissipation capacity.

If a structure experienced excessive peak deformation during a major earthquake, there will be a large residual deformation in a few stories of the structure after the earthquake. However, due to the plastic deformation of $\mathrm{CB}$ and $\mathrm{BRB}$ under the action of unreasonable axial force, the structure will not be recovered easily, which will lead to a long time to repair and high repairing costs after an earthquake.

In order to solve the above problems of $\mathrm{CB}$ and $\mathrm{BRB}$, some self-centering energy dissipation (SCED) braces or devices as excellent candidates are proposed to reduce or eliminate residual deformation of frame structures [3]. The thermal behavior of shape memory alloy (SMA) superelastic wires endows SMA-based devices with self-recentering capacity, and the use of those devices in the seismic protection of structures has shown that its advantage comes from the double-flag-shape of their hysteresis loops [4]. Other researchers have proposed various devices for recentering and energy dissipation using SMA. For example, Yang et al. [5, 6] installed the energy dissipation device and SMA outside two steel tubes that could be staggered to form a new steel-SMA hybrid device.

Using prestressed elastic materials to obtain recentering capacity is a more concerned approach. The scholar 
Tremblay et al. [7] proposed a new type of self-centering energy dissipation brace. The seismic response of multistory steel-framed buildings with SCED bracing members was examined (Tremblay et al.), and nonlinear incremental static analysis and dynamic analysis showed that the SCED frames generally experienced smaller peak story drifts, less damage concentration over the building height, and smaller residual lateral deformations compared to the BRB system. Liu et al. [8-10] proposed self-centering and buckling restrained braces using prestress steel strand to provide recentering force, and the braced structure was evaluated. He et al. [11] designed the self-centering energy dissipation rocking column by installing several self-recentering energy dissipation corner braces at the end of rocking columns. Xu et al. [12-14] proposed a new type of self-centering energy dissipation brace with a preloaded disc spring, which has good deformation capacity and energy dissipation capacity. Zhou $[15,16]$, a scholar from Taiwan, proposed a dual-core selfcentering brace, which uses I-shaped steel and square steel tube as the outer casing, and his research shows that the brace has good self-centering and energy dissipation properties.

SCED braces are generally composed of an energy dissipation system, a self-centering system, and a set of force transmission devices [17]. Some of the self-centering systems/braces use frictional energy dissipation mechanisms, but the aging and stability of the friction surfaces is a tricky problem when using this method of energy dissipation [18]. Moreover, most of the current SCED braces can only output the set friction force in its working process, so the corresponding friction force cannot be changed according to the response process of the structure during an earthquake. If an active or semiactive method is introduced to realize the intelligent variable friction, the manufacturing cost of those braces which are named smart braces will be significantly increased.

A more easily accepted and applied method is to take advantage of a mechanical method to realize the variability of the friction force, which is relatively a low cost and in essence a passive control method. Usually in the process of structural vibration under a strong earthquake, when story drift is getting bigger and bigger, that is to say, when a floor is far away from its original equilibrium position, it is hoped that those diagonal braces can provide relatively greater recentering capacity and friction force to prevent excessive story drifts. On the other hand, when story drift is small, a relatively small friction resistance of the brace is assigned such that structural restoration is prone to be realized. To achieve the above purpose, a new type of self-centering variable friction (SCVF) brace to realize variable output friction is proposed and had been tested.

\section{Experimental Work}

2.1. Specimens. A SCVF brace specimen is designed and manufactured, and the configuration and main dimension parameters of this prototype are given in Figure 1. The section of the specimen is rectangular, similar to other selfcentering devices; this SCVF brace also mainly consists of four parts: an inner tube, an outer tube, a tensioning system, and an energy dissipation system.

One end of the inner tube 1 and the other end of the outer tube 2 are welded to the end plates 10 and 12, respectively. On the left-hand side and right-hand side of the SCVF brace, the end connection components 11 and 13 with a circular hole of $30 \mathrm{~mm}$ in diameter are fitted to the end plate, which are convenient to be installed in the building structure that needs to mitigate vibration. This SCVF brace is usually installed in the position where a conventional energy dissipation brace is located.

The right part of the inner tube is provided with an $80 \mathrm{~mm}$ long slot on its upper and low plates, and the outer tube is also provided with two equally large slots as those on the inner tube near both ends. The location of the slot on the outer tube near the right end corresponds to the slot of the inner tube so that those slots on the left side of the outer tube are the left slots set, and the slots on the right side of the outer tube and the slots on the inner tube are the right slots set. Two guiding bolts 3 pass through the two sets of slots, respectively, and these bolts provide anchorage for the tensioning system. These two-slot sets and guiding bolts comprise a series of guiding elements of the SCVF brace. The tensioning force of the tensioning system is provided by a steel spring 4 which is located in the inner tube, and the two ends of the spring are, respectively, anchored on the two bolts.

A ceramic friction block 5 and a bendable friction steel plate 9 are installed between the inner tube and the outer tube. The surface between the ceramic block and the bendable steel plate forms a friction interface. Relative motion between the two tubes can activate the friction interface because the ceramic block and the bendable steel plate are fitted to the outer tube and the inner tube, respectively.

An adjusting screw bolt 8 is installed at the middle parts of the upper side and the lower side of the outer tube, respectively, and the end of the bolt which is screwed into the outer tube is against the ceramic block. By adjusting the depth of the screw bolt, the bending curvature of the friction steel plate can be changed so as to change the friction resistance during the relative motion process. The bendable friction steel plate is similar to a simply supported beam which has a flexural deformation subjected to transverse concentrated force. It is appropriate to use the deflection at the midpoint of the friction steel plate to indicate its bending degree.

The inner tube end plate is provided with a circular hole, as shown in Figure 1(d), to provide operational space for changing the pretension applied on the steel spring. The design parameters of components are shown in Table 1, and the parameters of the materials used in the specimen are listed in Table 2.

2.2. Test Setup. The quasistatic loading method was used in the test of the specimen of the SCVF brace. In order to obtain the force deformation relationship of the specimen, the deformation control loading mode with an equal loading 


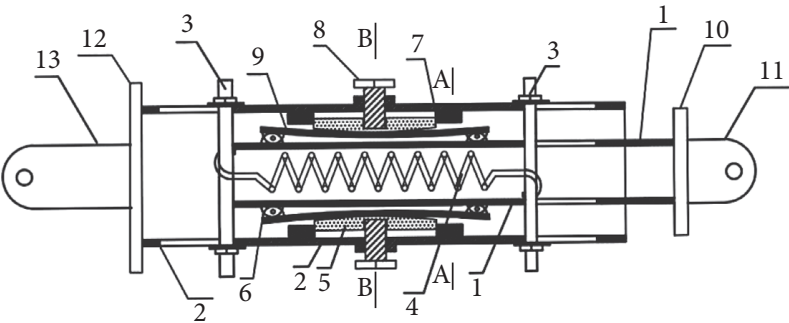

(a)

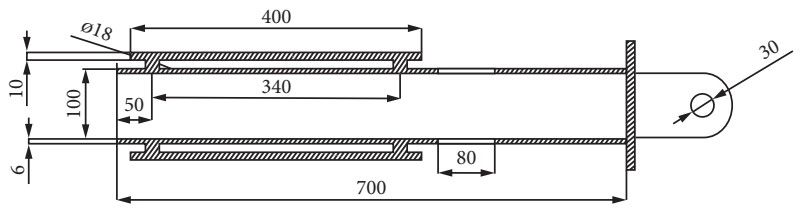

(c)

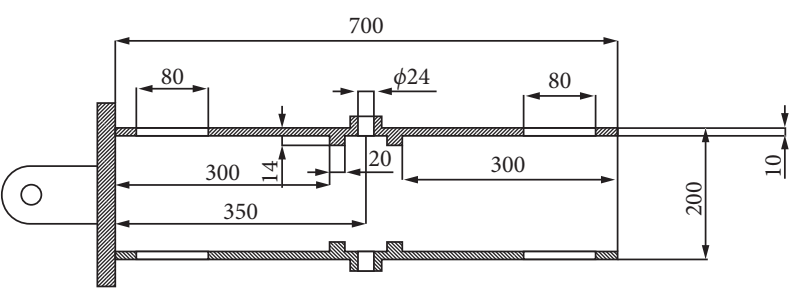

(b)

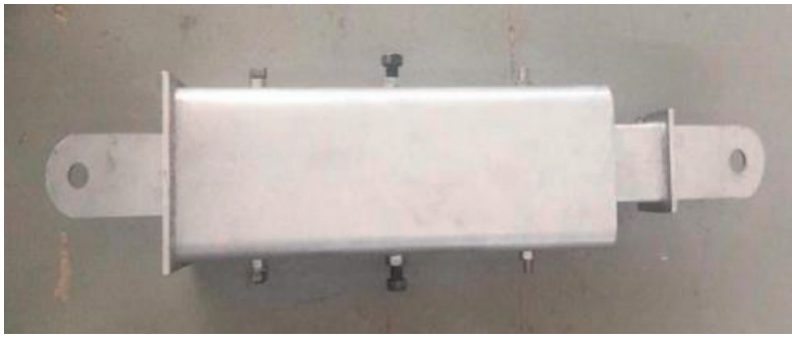

(d)

FIGURE 1: Design dimensions of the main parts and SCVF brace specimen. (a) The overall structure of the proposed SCVF brace. 1: inner tube; 2: outer tube; 3: guiding bolt; 4: tension spring; 5: ceramic friction block; 6: fixed hinge support assembly; 7: limit block; 8: adjusting screw bolt; 9: friction steel plate; 10: inner tube end plate; 11: inner tube connector; 12: outer tube end plate; 13: outer tube connector. (b) Size of the outer tube of the SCVF brace ( $\mathrm{mm}$ ). (c) The size of the inner tube of the SCVF brace (mm). (d) Specimen of the SCVF brace (axial scale compressed).

TABLE 1: Specimen design parameters.

\begin{tabular}{|c|c|c|c|c|}
\hline Part number & Name & Materials & Size parameters & Number \\
\hline 1 & Inner tube & Q235 & $100 \times 100 \mathrm{~mm}$ & 1 \\
\hline 2 & Outer tube & Q235 & $200 \times 200 \mathrm{~mm}$ & 1 \\
\hline 3 & Guiding bolt & Q345 & M18 & 2 \\
\hline 4 & High-strength spring S1 & Carbon spring steel & $\Phi 12 \times 80 \times 250 \mathrm{~mm} \times \mathrm{c} 17$ (China) & 1 \\
\hline 5 & High-strength spring S2 & Carbon spring steel & $\Phi 10 \times 80 \times 250 \mathrm{~mm} \times \mathrm{c} 20($ China $)$ & 1 \\
\hline 6 & Friction block & Ceramic fiber & $100 \times 60 \times 20 \mathrm{~mm}$ & 2 \\
\hline 7 & Hinge support assembly & Q235 & $\Phi 12$ & 4 \\
\hline 8 & Limit block & Q235 & $100 \times 20 \times 14 \mathrm{~mm}$ & 4 \\
\hline 9 & Adjusting bolt & Q235 & Grand 8.8 M24 (GB) & 2 \\
\hline 10 & Friction steel plate & Q235 & $400 \times 100 \times 10 \mathrm{~mm}$ & 2 \\
\hline 11 & Inner tube end plate & Q235 & $150 \times 150 \times 10 \mathrm{~mm}$ & 1 \\
\hline 12 & Inner tube connector & Q235 & $250 \times 100 \times 10 \mathrm{~mm}$ & 1 \\
\hline 13 & Outer tube end plate & Q235 & $250 \times 250 \times 10 \mathrm{~mm}$ & 1 \\
\hline 14 & Outer tube connector & Q235 & $250 \times 100 \times 10 \mathrm{~mm}$ & 1 \\
\hline
\end{tabular}

rate was used in the test process. This test was carried out on YAW-2000 portal vertical loading equipment which is a universal testing machine. The loading mechanism includes constant amplitude loading and variable amplitude loading, and the loading device is shown in Figure 2. The entire process was automatically controlled by a computer. The software POP-ware-2000c recorded the loading and unloading rate, axial deformation amplitude, and loading and unloading conditions automatically.

Before the experiment, the testing machine was employed to load the prototype SCVF brace with harmonic loading consisting of sufficient cycles at $\pm 10 \mathrm{~mm}$ amplitude and a loading frequency of $0.1 \mathrm{~Hz}$ until there was no abnormal noise inside the specimen.
For the proposed brace to function, the steel spring must be capable of producing the desired restoring force. As shown in Figures 2(a) and 2(b), springs S1 and S2 were stretched and tested to obtain their elastic coefficients. Under the condition that the testing loading rate is $10 \mathrm{~mm} /$ min and the loading amplitude is $40 \mathrm{~mm}$, the elastic stiffness of the two springs is determined to be 55.2 and $28.5 \mathrm{kN} / \mathrm{mm}$, respectively.

In the testing of friction coefficient correlation, two friction steel plates with the same properties were selected, one of which was sandblasted at the friction interface as shown in Figure 3. According to the test result, the friction coefficient of the sandblasted friction steel plate is 0.5 and that of another one is 0.4 , which can match the provision of 
TABLE 2: Mechanical parameters of Q235 and Q345.

\begin{tabular}{lcccc}
\hline Material & Tensile strength $(\mathrm{MPa})$ & Yield strength $(\mathrm{MPa})$ & Elastic modulus $(\mathrm{GPa})$ & Density $\left(\mathrm{g} / \mathrm{cm}^{3}\right)$ \\
\hline Q235 & $370-500$ & 235 & $200-210$ & 7.85 \\
Q345 & $490-675$ & 345 & $200-210$ & 7.85 \\
\hline
\end{tabular}

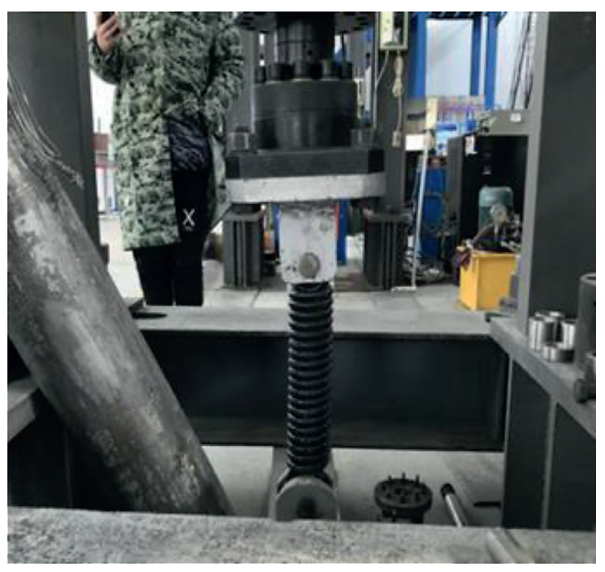

(a)

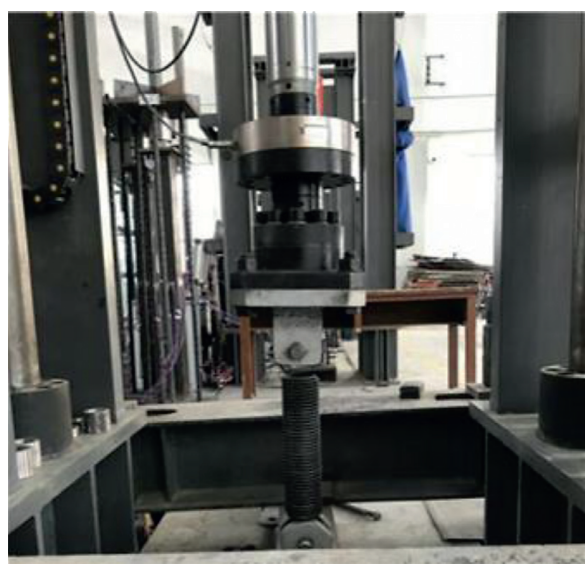

(b)

Figure 2: Test setup of tension spring. (a) Tension test of spring S1. (b) Tension test of spring S2.

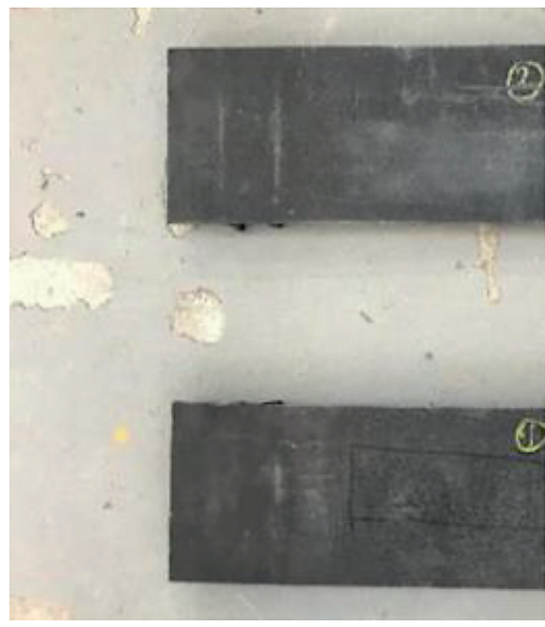

(a)

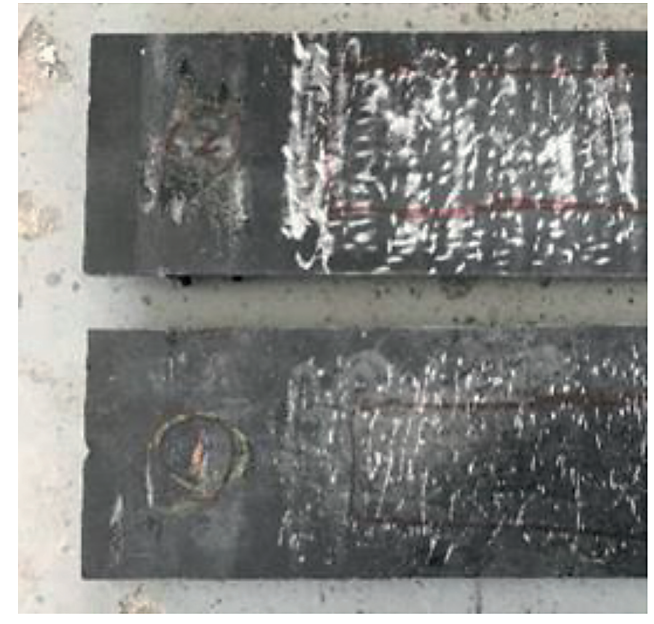

(b)

Figure 3: Changes in friction steel plates before and after treatment. (a) Friction steel plate before treatment. (b) Friction steel plate after treatment.

the Technical Code for Energy Dissipation and Damping of Buildings (JGJ2972013, CN) [19, 20].

In this testing, the SCVF brace specimen was installed on the testing machine, and a series of low-cyclic reversed variable amplitude loading tests were carried out to examine the hysteresis characteristics of the SCVF brace under different amplitude loading. Through these tests, the influence of spring stiffness, friction coefficient, and various axial deformation amplitude on the dissipation ability of the SCVF brace is studied under the condition of different bending degrees of the friction steel plates. The relevant Chinese code mentioned earlier $[19,20]$ clearly specifies the requirements for mechanical properties related to fatigue of friction type energy damper. This study tested the fatigue performance of this SCVF brace according to those guiding principles. In fatigue testing, an equal amplitude loading mechanism with an amplitude of $40 \mathrm{~mm}$ and a loading rate of $40 \mathrm{~mm} / \mathrm{min}$ was applied.

According to the above test contents, five test schemes are adopted. The detailed parameters of each scheme are listed in Table 3. 
TABLE 3: Experimental loading schemes.

\begin{tabular}{lcccc}
\hline Testing case & $\begin{array}{c}\text { Spring stiffness (N/ } \\
\mathrm{mm})\end{array}$ & $\begin{array}{c}\text { Loading amplitude } \\
(\mathrm{mm})\end{array}$ & $\begin{array}{c}\text { Deflection of friction plate } \\
(\mathrm{mm})\end{array}$ & $\begin{array}{c}\text { Coefficient of } \\
\text { friction }\end{array}$ \\
\hline $\begin{array}{l}\text { Effect of spring stiffness } \\
\text { Coefficient of friction }\end{array}$ & $28.5,55.2$ & 60 & $5,7.5$ & 0.4 \\
$\begin{array}{l}\text { Axial deformation } \\
\text { amplitude }\end{array}$ & 55.2 & $20,40,60$ & $5,7.5$ & $0.4,0.5$ \\
$\begin{array}{l}\text { Deflection of the friction } \\
\text { plate }\end{array}$ & $28.5,55.2$ & $20,40,60$ & $5,7.5$ & 3 \\
Fatigue test & $28.5,55.2$ & $20,40,60$ & $5,7.5$ & 3 \\
\hline
\end{tabular}

\section{Experimental Results and Analysis}

3.1. Effects of Spring Stiffness. Figures 4(a) and 4(b) show the hysteretic responses of the SCVF brace with 5 and $7.5 \mathrm{~mm}$ deflection of the friction steel plates, respectively. Two different colored curves in each figure represent the result of the SCVF brace installed spring S1 or spring S2.

It can be observed in the figure that hysteretic curves of the SCVF brace with different bending friction plates are roughly the same in shape that exhibits a flag-shaped response of this novel brace. Careful observation shows that there is a slight difference between the flag-shaped hysteresis curve of SCVF and SCED, and the difference is that the upper and lower edges of the flag-shape curve of the SCVF brace are not parallel while those of SCED brace are parallel. The hysteresis curve of SCVF is an atypical flag-shape curve.

By comparison, hysteresis curves of that brace with $7.5 \mathrm{~mm}$ deflection of the friction plate indicate that its energy dissipation capacity is more sufficient. Moreover, the activation load and the peak load at maximum axial deformation of the SCVF brace with the spring of greater stiffness are larger.

It is noted that a slight axial deformation occurred to the brace specimen with spring S2 at the onset of loading by testing machine, while this phenomenon is not obvious in the testing of the specimen with spring S1. In addition, the hysteresis curve of testing the brace with spring S2 shows some unsmooth steps and tiny serrations during the loading and unloading process, which may be caused by some small gaps among the components of the specimen. The loaddeformation curves of testing the brace with the spring S1 are smoother, which means that the higher pretensioning force of the SCVF brace is helpful to assemble all parts of the brace into a whole tightly.

According to the hysteretic curve obtained from the test, the parameters of energy dissipation performance of the SCVF brace under different spring conditions are calculated, as shown in Table 4. Compared with the brace installed with spring S2, the testing result shows that the energy dissipation ability of the brace installed with spring $\mathrm{S} 1$ increases by $6.2 \%$ and $2.5 \%$, respectively, in one hysteretic loop and the secant stiffness increases by 40.1 and $41.3 \%$ under the condition of the two kinds of 5 and $7.5 \mathrm{~mm}$ deflection of the friction plate, respectively, while the equivalent damping ratio of the brace with spring S2 is lower.
3.2. Effects of Deformation Amplitude. Figures 5 and 6 show the hysteresis curves of the brace installed with springs S1 and S2, respectively. The shapes of load-deformation response curves of the SCVF brace are all "flag-type" under various deformation amplitudes. It can be found that with the amplitude of axial tensile and compressive loading increasing, the dissipated energy of the SCVF braces increases, while the activation load of the SCVF brace does not change. Although different spring and friction plates were used, the brace showed its stable self-centering ability and dissipation energy capacity within the desired axial deformation.

From Figures 5 and 6, it can also be noted that the characteristic of variable friction of the SCVF brace is not obvious when the spring with larger stiffness is installed, but the characteristic of variable friction is more prominent when the spring with the smaller stiffness is used.

The parameters of energy dissipation performance of the SCVF brace under different deformation amplitudes are calculated according to the hysteretic curve obtained from the test, as shown in Tables 4 and 5 . It can be found from Tables 5 and 6 that the three mechanical parameters of the SCVF brace with the two different types of tension springs have similar changes. With the magnitude of the brace deformation increasing, the dissipated energy increases exponentially, while the secant stiffness and equivalent damping ratio show a decreasing trend. When the deformation amplitude is in the range of $20 \mathrm{~mm}$ to $60 \mathrm{~mm}$ for the SCVF brace with different tension springs S1 and S2, the secant stiffness is reduced by 52.3 and $56.2 \%$, respectively, and the equivalent damping ratio is decreased by 5.2 and $14.1 \%$, respectively.

3.3. Effects of the Friction Plate Deflection. The hysteresis curves of the SCVF brace with springs S1 and S2 are illustrated in Figure 7, in which different colored loops represent different braces with 5 or $7.5 \mathrm{~mm}$ deflection of the friction plate.

It can be seen from the figure that the friction plate with larger deflection can make the dissipated energy of the brace more sufficient under the same other conditions. When the spring stiffness is large, increasing the bending degree of the friction plate does not make the variable friction characteristics of the support more obvious. 


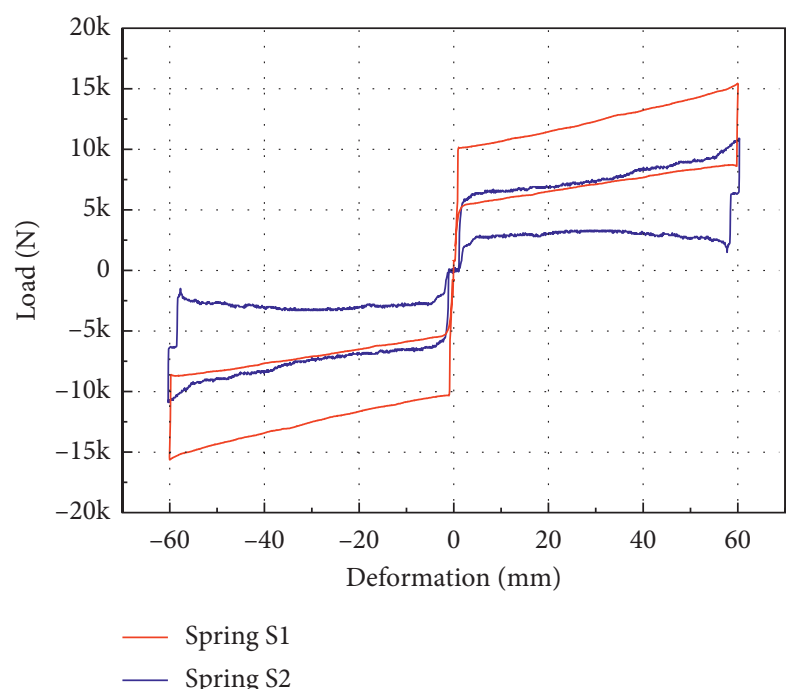

(a)

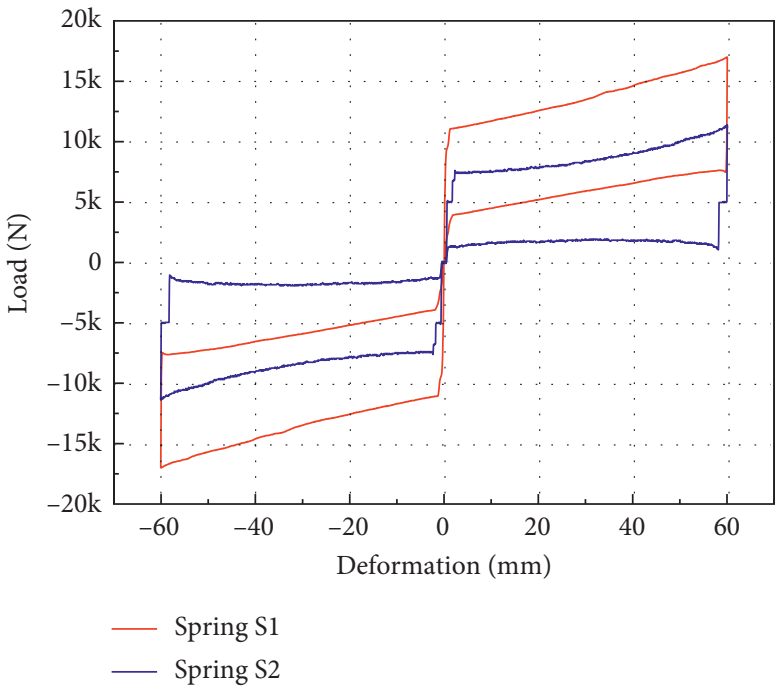

(b)

FIGURE 4: Load-deformation response of SCVF brace with different springs. (a) $5 \mathrm{~mm}$ deflection of the friction plate. (b) $7.5 \mathrm{~mm}$ deflection of the friction plate.

TABLE 4: Performance parameters of SCVF brace with different springs.

\begin{tabular}{lcccc}
\hline Deflection of the friction plate $\omega(\mathrm{mm})$ & Spring stiffness $K_{0}(\mathrm{~N} / \mathrm{mm})$ & $\begin{array}{c}\text { Energy } \\
\text { dissipation } W_{d}(\mathrm{~J})\end{array}$ & $\begin{array}{c}\text { Secant stiffness } \\
K_{s}(\mathrm{kN} / \mathrm{mm})\end{array}$ & $\begin{array}{c}\text { Equivalent damping } \\
\text { ratio }(\%)\end{array}$ \\
\hline \multirow{2}{*}{5} & (Spring S2) 28.5 & 565.674 & 0.178 & 13.659 \\
& (Spring S1) 55.2 & 600.010 & 0.256 & 10.319 \\
\hline \multirow{2}{*}{7.5} & (Spring S2) 28.5 & 877.523 & 0.197 & 18.435 \\
& (Spring S1) 55.2 & 898.689 & 0.283 & 14.209 \\
\hline
\end{tabular}

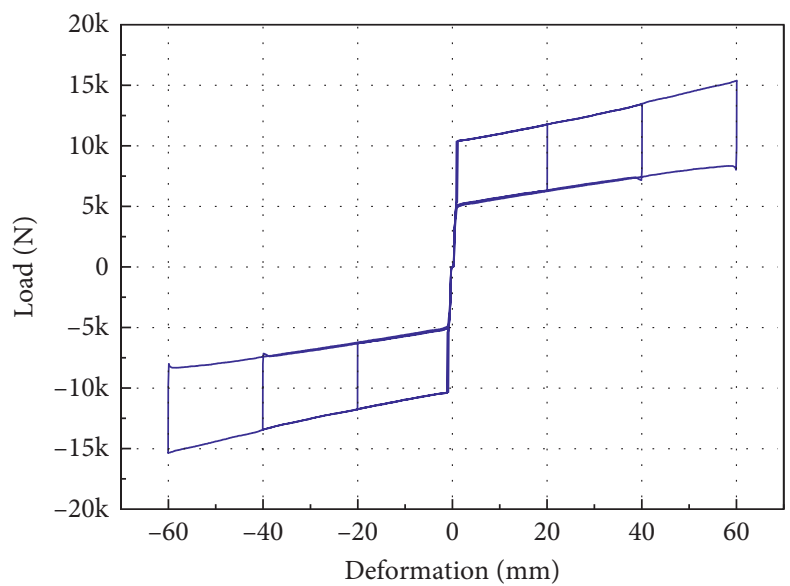

(a)

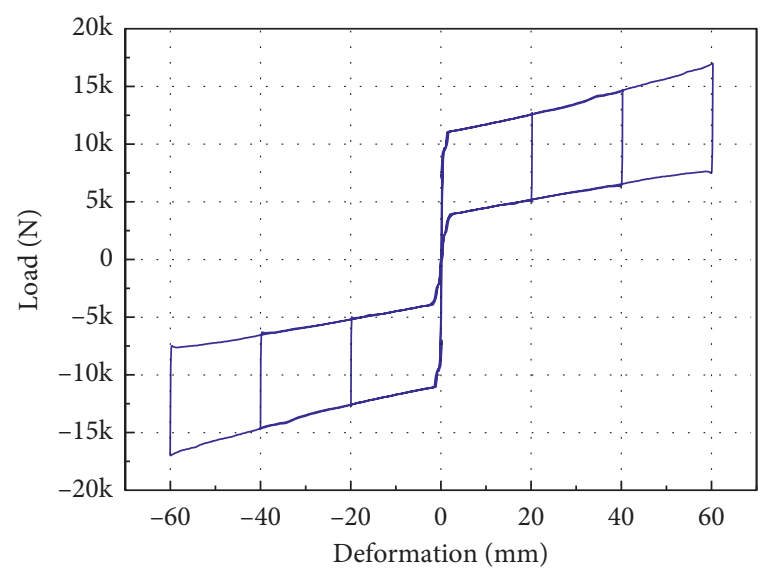

(b)

FIGURE 5: Hysteresis curve under various deformation amplitude (SCVF brace with spring S1). (a) $5 \mathrm{~mm}$ deflection of the friction plate and (b) $7.5 \mathrm{~mm}$ deflection of the friction plate.

The parameters of energy dissipation performance of the SCVF brace with different deflections of the friction plate, which are calculated according to the hysteretic curve obtained from the test, are shown in Table 7. When the SCVF brace with spring $\mathrm{S} 1$ and the deflection of the friction plate is changed from 5 to $7.5 \mathrm{~mm}$, the energy dissipation of the SCVF brace increases by $56.3 \%$, the secant stiffness of the SCVF brace increases by $14.9 \%$, and the equivalent damping 


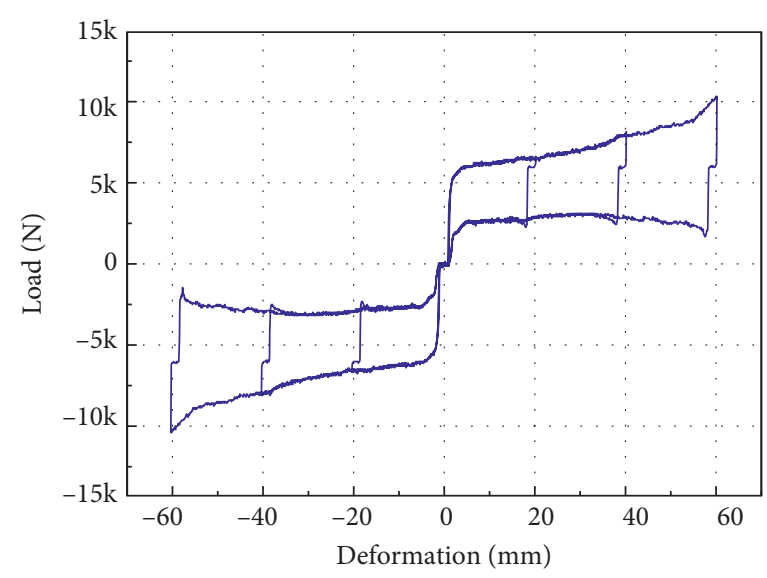

(a)

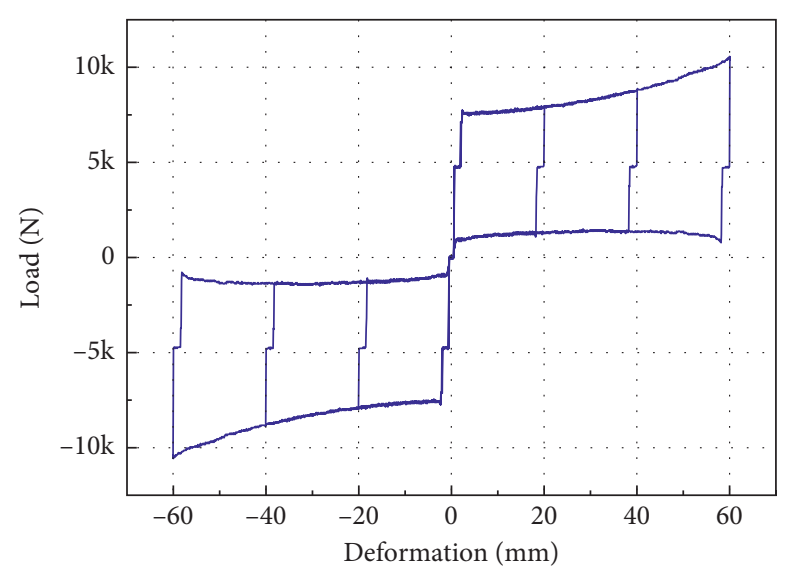

(b)

FIGURE 6: Hysteresis curve under various deformation amplitude (SCVF brace with spring S2). (a) 5 mm deflection of the friction plate and (b) $7.5 \mathrm{~mm}$ deflection of the friction plate.

TABle 5: Performance parameters under various deformation amplitude (SCVF brace with spring S1).

\begin{tabular}{lcccc}
\hline $\begin{array}{l}\text { Deflection of the friction plate } \\
\omega(\mathrm{mm})\end{array}$ & $\begin{array}{c}\text { Deformation amplitude } \delta_{\max } \\
(\mathrm{mm})\end{array}$ & $\begin{array}{c}\text { Energy dissipation } \\
W_{d}(\mathrm{~J})\end{array}$ & $\begin{array}{c}\text { Secant stiffness } K_{s} \\
(\mathrm{kN} / \mathrm{mm})\end{array}$ & $\begin{array}{c}\text { Equivalent damping ratio } \\
(\%) \xi_{\mathrm{eq}}\end{array}$ \\
\hline & 20 & 132.216 & 0.351 & 15.348 \\
5 & 40 & 311.712 & 0.209 & 14.474 \\
& 60 & 565.674 & 0.178 & 13.659 \\
\hline & 20 & 206.145 & 0.453 & 18.127 \\
& 40 & 505.497 & 0.250 & 18.186 \\
& 60 & 877.523 & 0.197 & 18.435 \\
\hline
\end{tabular}

TABLE 6: Performance parameters under various deformation amplitudes (SCVF brace with spring S2).

\begin{tabular}{lcccc}
\hline $\begin{array}{l}\text { Deflection of the friction plate } \\
\omega(\mathrm{mm})\end{array}$ & $\begin{array}{c}\text { Deformation amplitude } \delta_{\max } \\
(\mathrm{mm})\end{array}$ & $\begin{array}{c}\text { Energy dissipation } \\
W_{d}(\mathrm{~J})\end{array}$ & $\begin{array}{c}\text { Secant stiffness } K_{s} \\
(\mathrm{kN} / \mathrm{mm})\end{array}$ & $\begin{array}{c}\text { Equivalent damping ratio } \\
(\%)\end{array}$ \\
\hline & 20 & 182.536 & 0.578 & 13.679 \\
5 & 40 & 387.026 & 0.335 & 12.635 \\
& 60 & 600.010 & 0.256 & 10.319 \\
7.5 & 20 & 286.772 & 0.627 & 16.151 \\
& 40 & 581.456 & 0.364 & 15.727 \\
\hline
\end{tabular}

ratio increases by $35.4 \%$. When the SCVF brace with spring S2 and the deflection of the friction plate is changed from $5 \mathrm{~mm}$ to $7.5 \mathrm{~mm}$, the energy dissipation of the SCVF brace increases by $52.3 \%$, secant stiffness of the SCVF brace increases by $10.1 \%$, and the equivalent damping ratio increases by $39.2 \%$.

3.4. Effects of Friction Coefficient. The results of low-cyclic loading tests on the SCVF brace with different friction coefficients are shown in Figure 8. Note that, under the condition of a larger friction coefficient, the energy dissipation capacity of the brace is stronger. In addition, irregular microbumps appear in the hysteresis curve with the increase of the friction coefficient; this may be because of the unevenness of the surface of the steel plate after sandblasting.
With the increase of the friction coefficient of the SCVF brace, its energy dissipation, secant stiffness, and equivalent damping ratio increase accordingly, which are shown in Table 8. Among them, under 5.5 and $7.5 \mathrm{~mm}$ deflections of the friction plate, dissipated energy of the SCVF brace increases by 38.8 and $37.4 \%$, respectively, after the steel plate is sandblasted.

3.5. Effects of Fatigue Performance. The hysteresis curves which are illustrated in Figure 9 are nearly overlapped in the graph when the SCVF brace is loaded the $30^{\text {th }}$ and the $1^{\text {st }}$ cycles. Comparisons between the curves of the first cycle and the $30^{\text {th }}$ cycle loading show the stable behavior of the brace specimen. However, after statistics of the test data of these two cyclic loadings which are presented in Table 9, it can also 


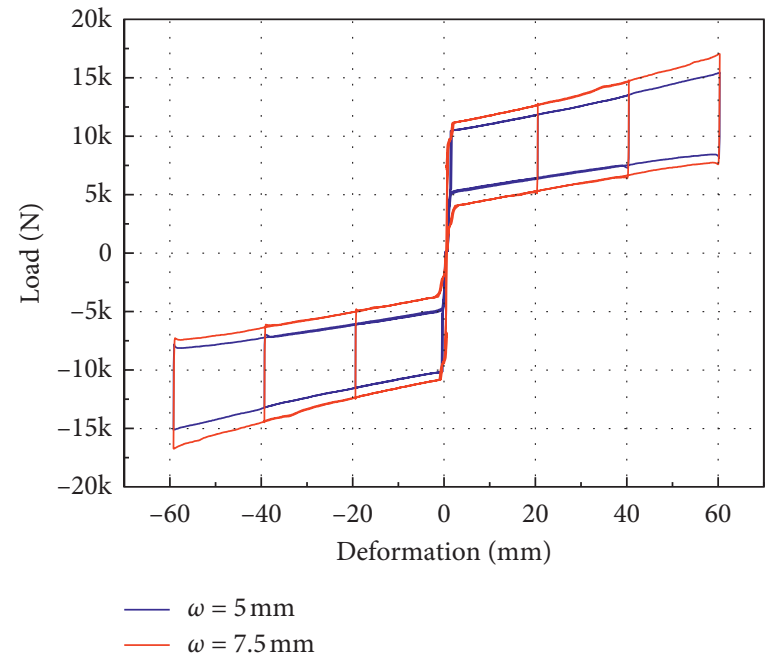

(a)

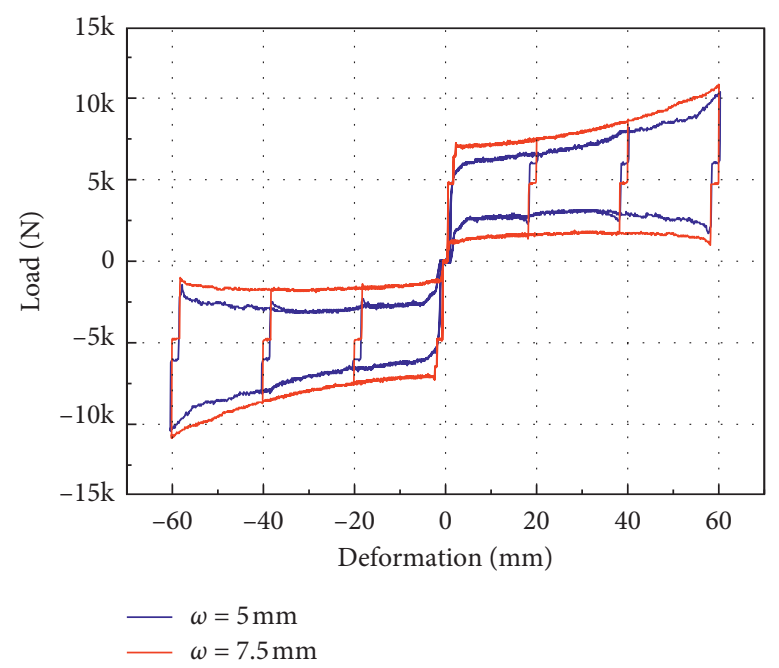

(b)

FIGURE 7: Hysteretic performance under 5 and $7.5 \mathrm{~mm}$ deflection of the friction plate. (a) Hysteresis curve of SCVF brace with spring S1. (b) Hysteresis curve of SCVF brace with spring S2.

TABLE 7: Mechanical parameters of SCVF brace under 5 and $7.5 \mathrm{~mm}$ deflection of the friction plate.

\begin{tabular}{lcccc}
\hline Spring stiffness $K_{0}(\mathrm{~N} / \mathrm{mm})$ & Deflection $w(\mathrm{~mm})$ & Energy dissipation $W_{d}(\mathrm{~J})$ & $\begin{array}{c}\text { Secant stiffness } K_{\mathrm{s}} \\
(\mathrm{kN} / \mathrm{mm})\end{array}$ & Equivalent damping ratio $(\%)$ \\
\hline \multirow{2}{*}{ Tension spring S2 28.5 } & 5 & 565.674 & 0.178 & 13.659 \\
& 7.5 & 877.632 & 0.210 & 18.435 \\
\hline \multirow{2}{*}{ Tension spring S1 55.2 } & 5 & 600.010 & 0.256 & 10.319 \\
\end{tabular}

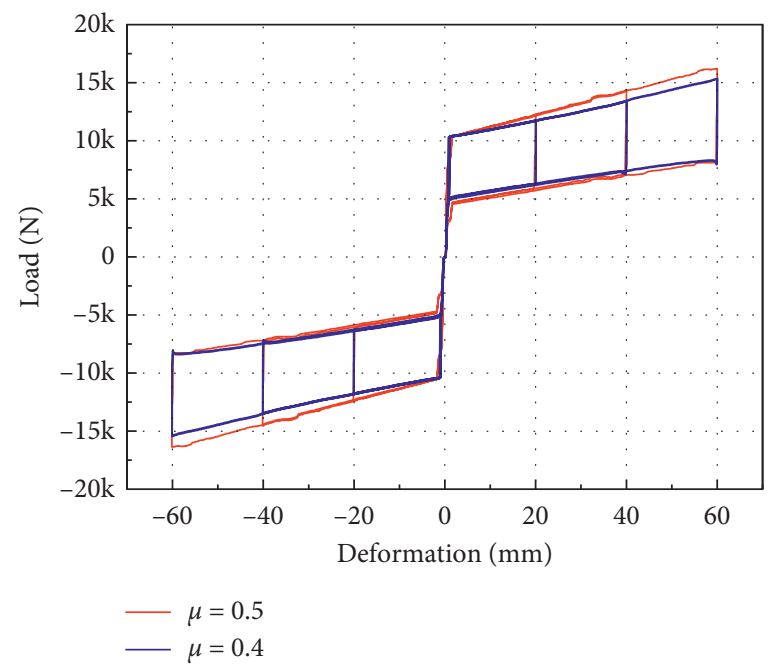

(a)

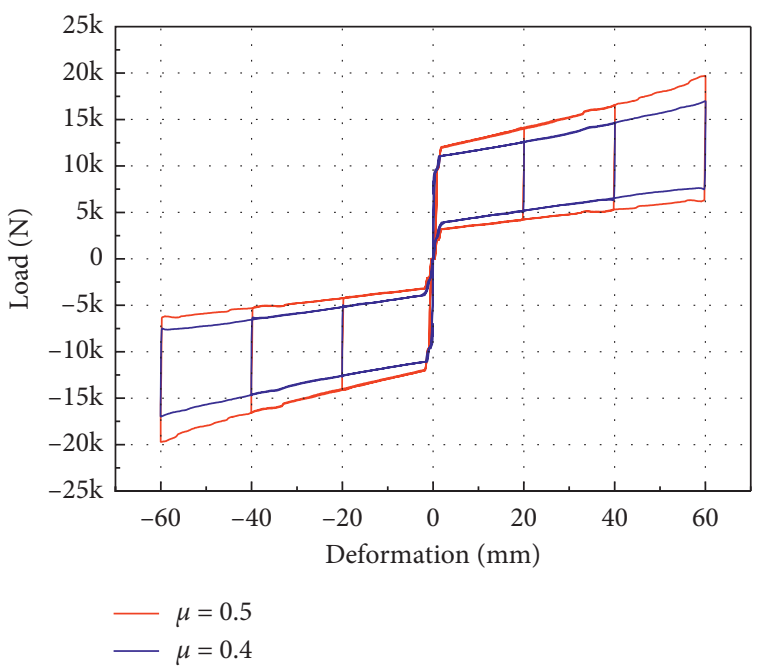

(b)

FIGURE 8: Hysteretic performance under different friction coefficients. (a) $5 \mathrm{~mm}$ deflection of the friction plate. (b) $7.5 \mathrm{~mm}$ deflection of the friction plate.

be noted that the performance of the specimen has changed slightly after repeated constant cyclic loading.

The testing result in Table 9 shows that the energy dissipation of the SCVF brace with spring S1 decreases by
$5.9 \%$ and another with spring S2 decreases by $6.6 \%$, which is less than the limit of $\pm 15 \%$ specified by the specification in China. The secant stiffness decreases by 3.7 and $1.2 \%$ and the equivalent damping ratio decreases by 3.1 and $4.8 \%$ when the 
TABLE 8: Mechanical parameters under different friction coefficients.

\begin{tabular}{lcccc}
\hline $\begin{array}{l}\text { Deflection of the friction plate } \omega \\
(\mathrm{mm})\end{array}$ & $\begin{array}{c}\text { Friction coefficient } \\
\mu\end{array}$ & $\begin{array}{c}\text { Energy dissipation } W_{d} \\
(\mathrm{~J})\end{array}$ & $\begin{array}{c}\text { Secant stiffness } \\
K_{s} \\
(\mathrm{kN} / \mathrm{mm})\end{array}$ & $\begin{array}{c}\text { Equivalent damping ratio }(\%) \\
\xi_{\mathrm{eq}}\end{array}$ \\
\hline \multirow{2}{*}{5} & 0.4 & 600.010 & 0.256 & 10.319 \\
& 0.5 & 814.632 & 0.271 & 13.270 \\
\hline .5 & 0.4 & 898.689 & 0.283 & 14.209 \\
& 0.5 & 1234.702 & 0.324 & 16.790 \\
\hline
\end{tabular}

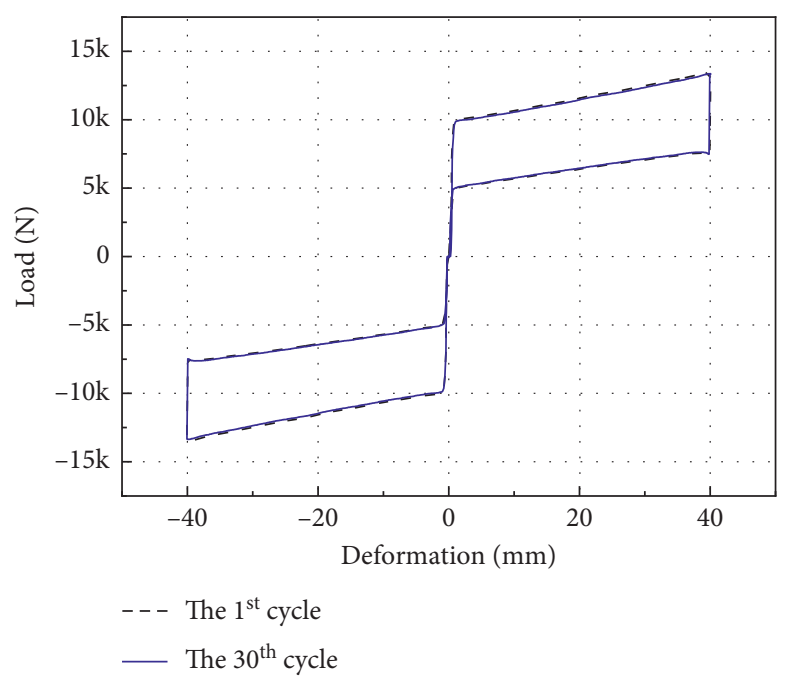

(a)

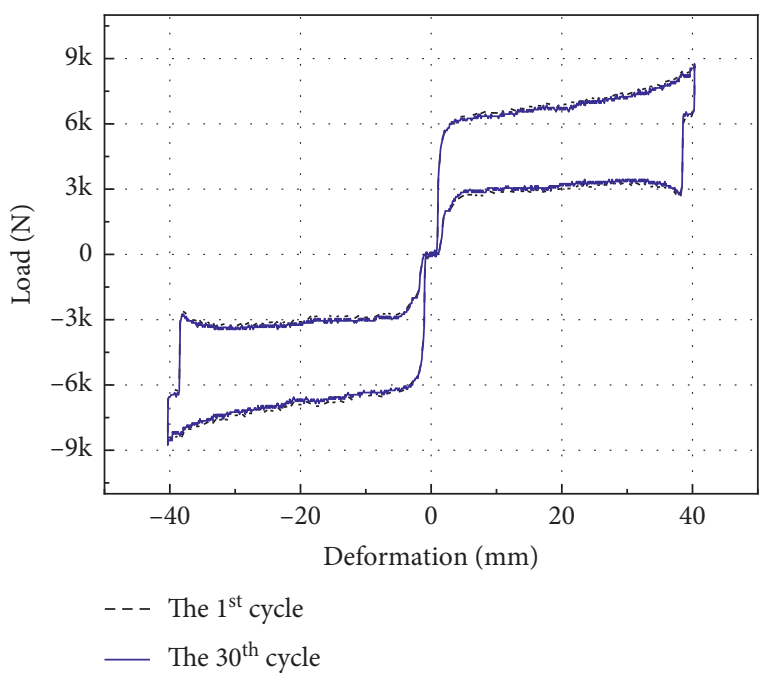

(b)

FIgURE 9: Comparison of hysteresis curves of the fatigue test. (a) Hysteresis curve of SCVF brace with spring S1. (b) Hysteresis curve of SCVF brace with spring S2.

TABle 9: Mechanical parameters under $5 \mathrm{~mm}$ deflection of the friction plate.

\begin{tabular}{lcccc}
\hline Spring & Load times & Energy dissipation $W_{d}(\mathrm{~J})$ & Secant stiffness $K_{s}(\mathrm{kN} / \mathrm{mm})$ & Equivalent damping ratio $(\%)$ \\
\hline \multirow{2}{*}{ Tension spring S1 } & 1st cycle & 308.251 & 0.219 & 13.967 \\
& 30th cycle & 290.152 & 0.211 & 13.535 \\
\hline \multirow{2}{*}{ Tension spring S2 } & 1st cycle & 385.733 & 0.336 & 12.358 \\
& 30th cycle & 360.266 & 0.332 & 11.761 \\
\hline
\end{tabular}

SCVF brace with spring S1 and spring S2, respectively. The reason for this phenomenon is that the friction interface of the SCVF brace becomes smooth and the friction force decreases after repeated loading by preliminary judgment.

The test results demonstrate that the mechanical parameters of the SCVF brace have not changed significantly under different working conditions; it further illustrates that the SCVF brace has a superior antifatigue performance. After the end of the fatigue test, all parts of the SCVF brace are intact and have no obvious bending, and the friction steel plate is always in the range of elastic change during the SCVF brace working. At the same time, repeated friction between the friction block and the surface of the friction steel plate makes the friction interface smooth, which in turn has a slight impact on the brace performance. From the experimental results, mechanical parameters of the SCVF brace have not changed much after the fatigue test and it also shows that the energy dissipation system formed by the ceramic fiber friction blocks and friction steel plates in the SCVF brace has a certain stability.

\section{Simulation versus Test Results}

There is no self-centering variable friction material defined in OpenSees material library. In this case, it is not possible to assign such SCVF material properties to energy dissipation elements for structural analysis. Based on the four-stage hysteresis curve of the SCVF brace shown in Figure 4, the SCVF material was added to the uniaxial material library on the open-source platform of the finite element software OpenSees. The compiling and debugging tool is Visual Studio, and the source code of OpenSees is version 2.5.0 (6248) from its official website. Figure 10 is the expectant constitutive model of the SCVF brace. Figure 11 is the flow 


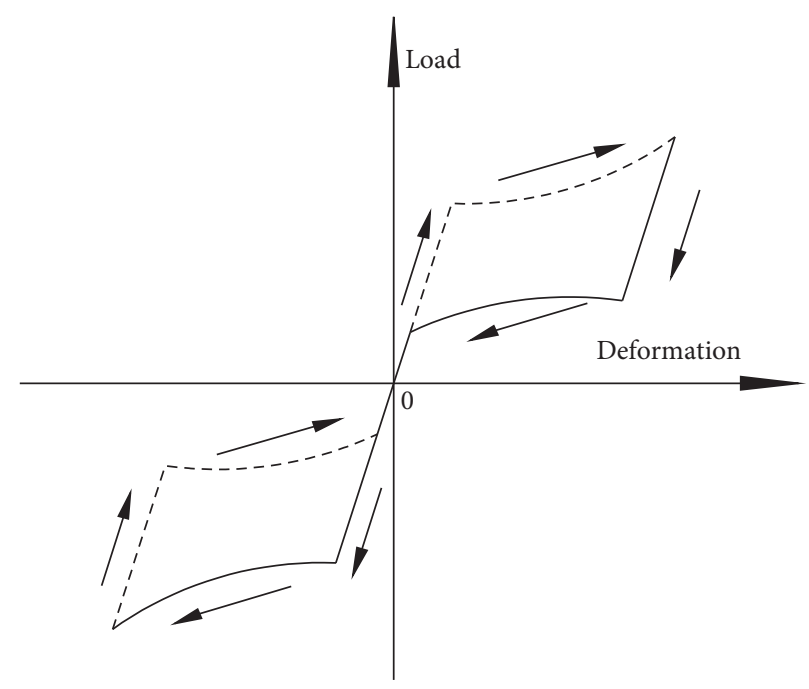

FIGURE 10: The expectant constitutive model of SCVF brace.

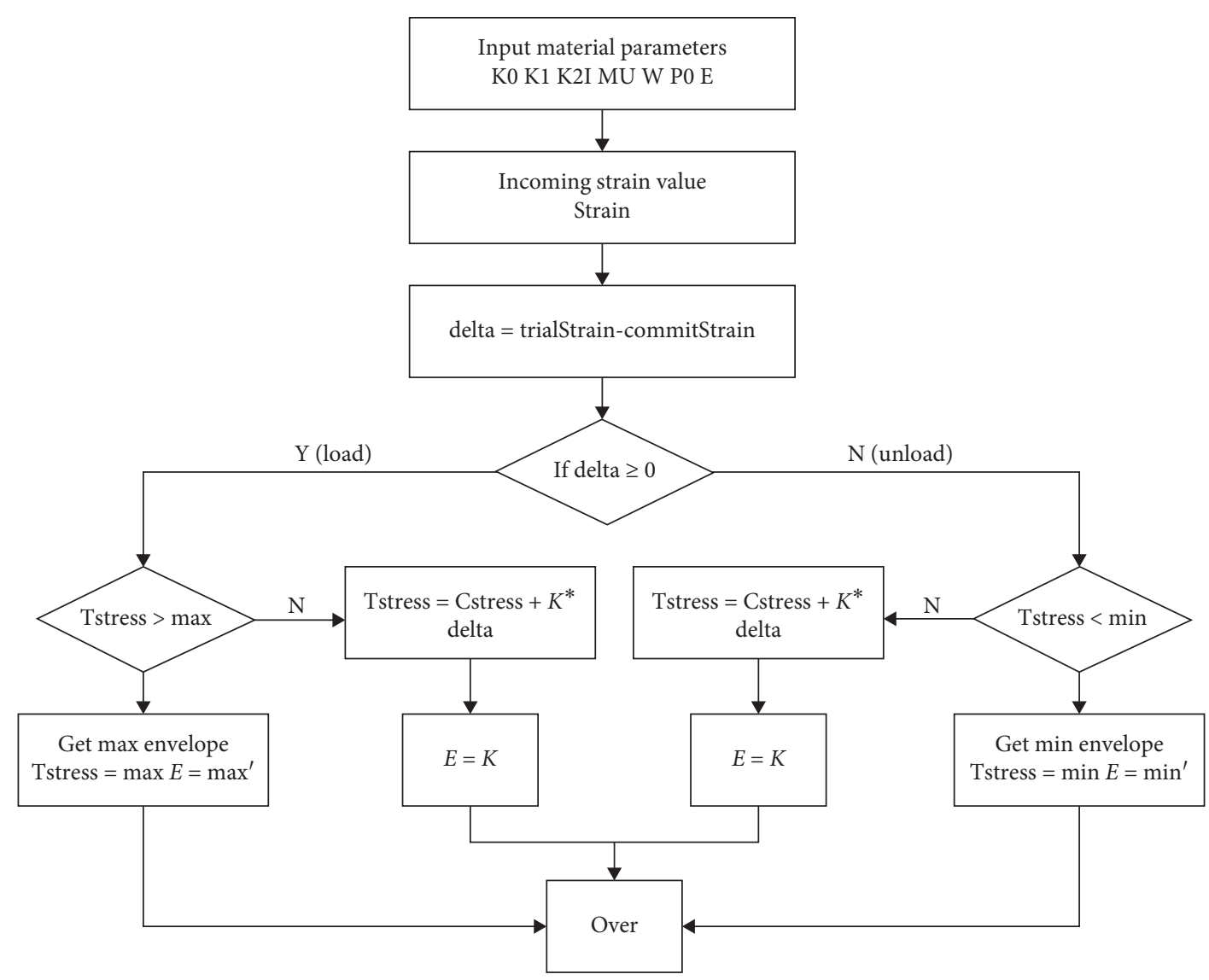

FIgURE 11: The flow chart of numerical SCVF material.

chart of the hysteresis loop path of the SCVF material constitutive model. The definition of member variables is detailed in Table 10. The brace element can be assigned according to the material and geometric parameters in Table 1, and the loading protocol of the numerical model has no difference with the test on the specimen so that the simulation of numerical testing can be compared with the testing result of the specimen.

Hysteresis curves of the SCVF brace which are obtained from the test and of the finite element model are presented in Figures 12 and 13, in which the testing and the simulation results of the SCVF brace with different spring stiffness 
TABLE 10: Main member variables of the SCVF material.

\begin{tabular}{lc}
\hline Name & Meaning \\
\hline setTrialStrain & Calculate current stress stiffness and so forth according to the actual strain \\
CommitStrain & Last step strain \\
getStrain & Last step stress \\
getStress & Return current strain \\
getTangent & Return current stress \\
srialStrain & Return tangent modulus \\
TStress & Real-time strain \\
getmaxenvelop & Real-time stress \\
getminenvelop & Get the max envelop value \\
\hline
\end{tabular}

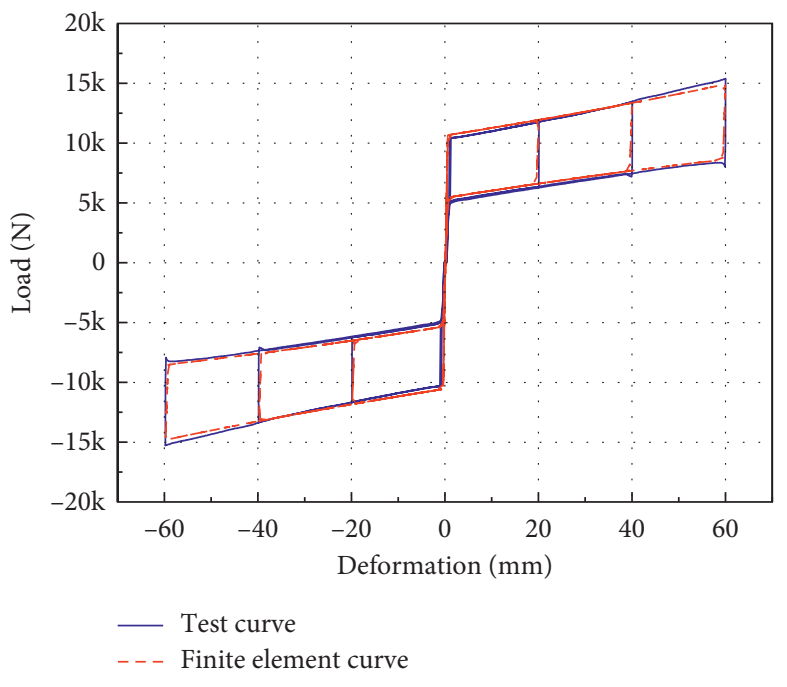

(a)

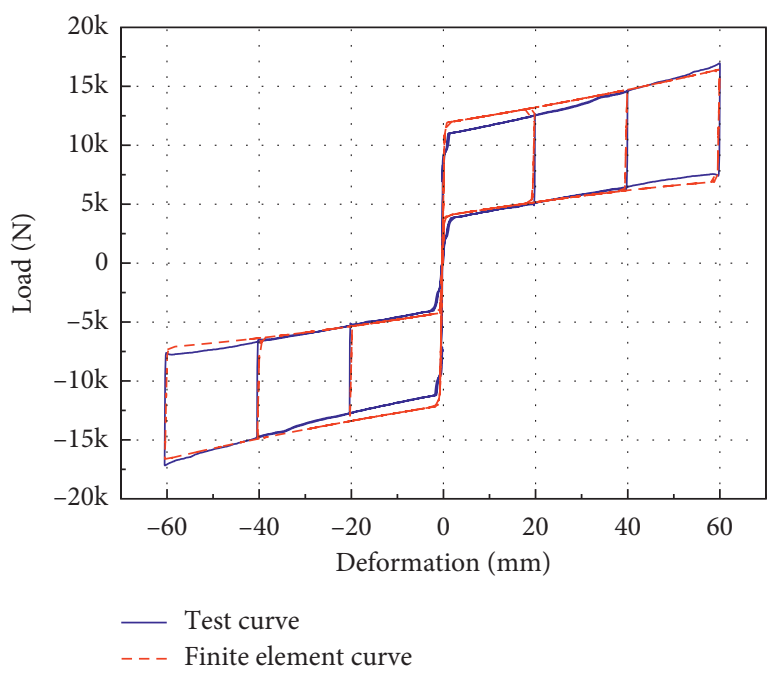

(b)

Figure 12: Hysteresis curves of test and finite element (SCVF brace with spring S1). (a) $5 \mathrm{~mm}$ deflection of the friction plate. (b) $7.5 \mathrm{~mm}$ deflection of the friction plate.

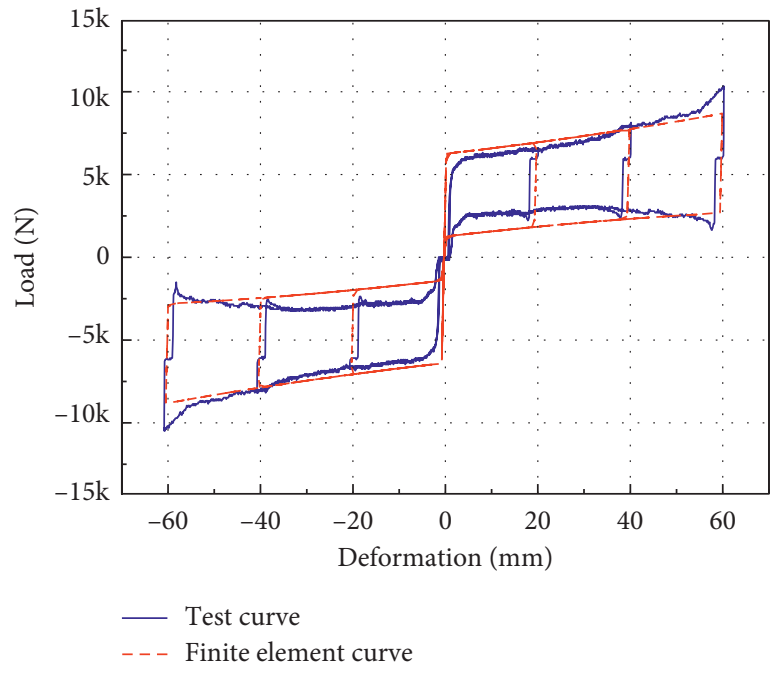

(a)

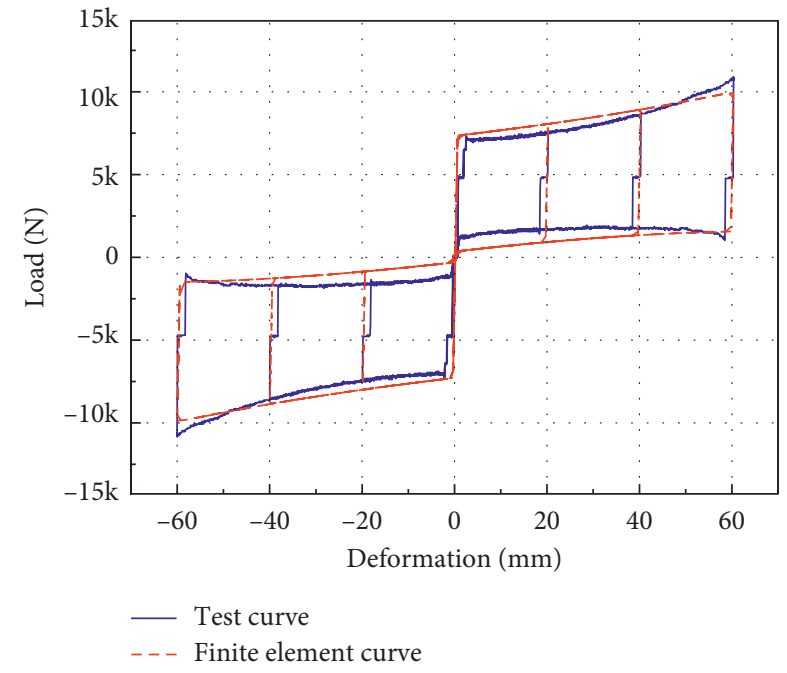

(b)

FIGURE 13: Hysteresis curves of test and finite element (SCVF brace with spring S2). (a) $5 \mathrm{~mm}$ deflection of the friction plate. (b) $7.5 \mathrm{~mm}$ deflection of the friction plate. 
TABLE 11: Mechanical parameters of the FEM simulation value versus test value (SCVF brace with spring S1).

\begin{tabular}{|c|c|c|c|c|c|c|c|c|c|}
\hline \multirow{2}{*}{$\begin{array}{l}\text { Midspan } \\
\text { deflection } \omega \\
(\mathrm{mm})\end{array}$} & \multicolumn{2}{|c|}{$\begin{array}{c}\text { Energy dissipation } W_{d} \\
(\mathrm{~J})\end{array}$} & \multirow{2}{*}{$\begin{array}{l}\text { Deviation } \\
\quad(\%)\end{array}$} & \multicolumn{2}{|c|}{$\begin{array}{c}\text { Secant stiffness } K_{s} \\
(\mathrm{kN} / \mathrm{mm})\end{array}$} & \multirow{2}{*}{$\begin{array}{l}\text { Deviation } \\
\quad(\%)\end{array}$} & \multicolumn{2}{|c|}{$\begin{array}{l}\text { Equivalent damping } \\
\text { ratio } \xi_{\text {eq }}(\%)\end{array}$} & \multirow{2}{*}{ Deviation (\%) } \\
\hline & $\begin{array}{c}\text { Test } \\
\text { value }\end{array}$ & $\begin{array}{l}\text { Simulation } \\
\text { value }\end{array}$ & & $\begin{array}{c}\text { Test } \\
\text { value }\end{array}$ & $\begin{array}{l}\text { Simulation } \\
\text { value }\end{array}$ & & $\begin{array}{c}\text { Test } \\
\text { value }\end{array}$ & $\begin{array}{l}\text { Simulation } \\
\text { value }\end{array}$ & \\
\hline 5 & 600.010 & 642.674 & 7.0 & 0.256 & 0.248 & 3.1 & 10.319 & 11.791 & 14.2 \\
\hline 7.5 & 898.689 & 993.109 & 10.5 & 0.283 & 0.274 & 3.2 & 14.209 & 15.979 & 112.4 \\
\hline
\end{tabular}

TABLE 12: Mechanical parameters of the FEM analog value versus test value (SCVF brace with spring S2).

\begin{tabular}{|c|c|c|c|c|c|c|c|c|c|}
\hline \multirow{2}{*}{$\begin{array}{l}\text { Midspan } \\
\text { deflection } \omega \\
(\mathrm{mm})\end{array}$} & \multicolumn{2}{|c|}{$\begin{array}{c}\text { Energy dissipation } W_{d} \\
(\mathrm{~J})\end{array}$} & \multirow{2}{*}{$\begin{array}{l}\text { Deviation } \\
\quad(\%)\end{array}$} & \multicolumn{2}{|c|}{$\begin{array}{l}\text { Secant stiffness } K_{s} \\
(\mathrm{kN} / \mathrm{mm})\end{array}$} & \multirow{2}{*}{$\begin{array}{l}\text { Deviation } \\
\quad(\%)\end{array}$} & \multicolumn{2}{|c|}{$\begin{array}{l}\text { Equivalent damping } \\
\text { ratio } \xi_{\text {eq }}(\%)\end{array}$} & \multirow{2}{*}{ Deviation (\%) } \\
\hline & $\begin{array}{c}\text { Test } \\
\text { value }\end{array}$ & $\begin{array}{l}\text { Simulation } \\
\text { value }\end{array}$ & & $\begin{array}{c}\text { Test } \\
\text { value }\end{array}$ & $\begin{array}{l}\text { Simulation } \\
\text { value }\end{array}$ & & $\begin{array}{c}\text { Test } \\
\text { value }\end{array}$ & $\begin{array}{l}\text { Simulation } \\
\text { value }\end{array}$ & \\
\hline 5 & 565.674 & 639.68 & 13.0 & 0.178 & 0.166 & & 13.748 & 16.430 & 16.3 \\
\hline 7.5 & 877.523 & 956.35 & 8.3 & 0.197 & 0.184 & 6.3 & 18.435 & 20.820 & 12.9 \\
\hline
\end{tabular}

under different deformation amplitude and deflection of the friction plate are compared. The results show that the hysteresis curves which are obtained from the numerical testing are highly agreeable with that from the experimental results, which demonstrate that the finite element model can effectively simulate the working characteristics of the SCVF brace.

The hysteresis performance between the finite element simulation value and the test value of the SCVF brace under different spring stiffness is compared in Tables 11 and 12 . Among them, it can be observed in Table 11 that the deviation of energy dissipation is the largest at $13 \%$ for the SCVF brace with springs S2 and $5 \mathrm{~mm}$ deflection of the friction plate, which meets the performance requirements of energy dissipation design value and measured value within $15 \%$ in the specification of China. The energy dissipation of the SCVF brace obtained from the test is less than the finite element analog value. It may be because the actual friction coefficient of the SCVF brace between the friction block and the friction steel plate is smaller than that of the finite element simulation. After comparison, it can be noted that the brace with a spring of smaller stiffness has a more obvious variable friction effect.

\section{Conclusions}

This paper presents a new type of SCVF brace and conducts experimental analysis on it. Based on the obtained results, the following three conclusions are listed.

The hysteresis curve of the SCVF brace shows an atypical "flag-type," which indicates that the SCVF brace has obvious variable friction characteristic and it also shows good selfcentering ability. The SCVF brace with low stiffness spring has more noticeable variable friction characteristics. In other words, the SCVF brace with high stiffness spring needs the friction plates with larger deflection to achieve obvious variable friction characteristics.

Although different spring and friction plates were used, the brace showed its stable self-centering ability and dissipation energy capacity within the permitted axial deformation. A larger deflection of the friction plate will make the variable friction of this SCVF brace more obvious. A higher friction coefficient will make the energy dissipation capacity of the SCVF brace stronger, but after repeated friction, the actual friction coefficient will be lower than the design value. The results of the fatigue test showed that the energy dissipation system formed by the ceramic fiber friction blocks and friction steel plates in the SCVF brace has a certain stability.

The test results are in good agreement with the results of finite element numerical simulation, and the load-deformation relationship of the device is very clear, which is conducive to the use of finite element software for calculation and structural analysis in engineering design. However, whether the SCVF brace is more effective in restraining the deformation response of the structure when the brace installs on the structure, it needs our further study.

\section{Data Availability}

The testing results used to support the findings of this study are included within the article.

\section{Conflicts of Interest}

The authors declare that there are no conflicts of interest regarding the publication of this paper.

\section{Authors' Contributions}

Qingguang He conceived the idea of this research and wrote the initial draft; Yanxia Bai organized and translated the paper; Weike Wu designed computer programs and did the test; and Qingguang $\mathrm{He}$ and Yongfeng $\mathrm{Du}$ reviewed and revised the paper. 


\section{References}

[1] R. Tremblay and N. Robert, "Seismic performance of low-and medium-rise chevron braced steel frames," Canadian Journal of Civil Engineering, vol. 28, no. 4, pp. 699-714, 2001.

[2] N. Wu, X. Gao, Z. Li, J. Ren, and H. Huang, "Experimental study on reinforced concrete frames retrofitted with in-filled steel frames and connected BRBS," Engineering Mechanics, vol. 30, no. 12, pp. 189-198, 2013, in Chinese.

[3] H. Xu and S. Yao, "Experimental study and finite element simulation on hyteretic performance of self-centering energy dissipation brace," Journal of Building Structures, vol. 39, no. 11, pp. 158-165, 2018, in Chinese.

[4] M. Dolce and D. Cardon, "Theoretical and experimental studies for the application of shape memory alloys in civil engineering," Journal of Engineering Materials and Technology, vol. 128, no. 3, pp. 302-311, 2006.

[5] C. S. Yang, R. Desroches, and R. T. Leon, "Design of hybrid braced frames," in Proceedings of the American Society of Civil Engineering Structures Congress, pp. 1544-1553, Orlando, FL, USA, May 2010.

[6] C. S. Yang, R. Desroches, and R. T. Leon, "Design and analysis of braced frames with shape memory alloy and energy-absorbing hybrid devices," Engineering Structures, vol. 32, no. 2, pp. 498-507, 2010.

[7] R. Tremblay, M. Lacerte, and C. Christopoulos, "Seismic response of multistory buildings with self-centering energy dissipative steel braces," Journal of Structural Engineering, vol. 134, no. 1, pp. 108-120, 2008.

[8] L. I. U. Lu, Seismic Behavior and Design of Structure with SelfCentering Buckling-Restrained Braces. Harbin, Harbin Institute of Technology, Shenzhen, China, 2013, in Chinese.

[9] L. I. U. Lu, B. Wu, L. I. Wei et al., "Key parameters of structure with self-centering buckling-restrained braces for seismic analysis," Engineering Mechanics, vol. 33, no. 1, pp. 188-194, 2016, in Chinese.

[10] L. I. U. Lu, B. Wu, L. I. Wei et al., "The application of the equivalent linearization methodology in self-centering buckling-restrained braced frames," Engineering Mechanics, vol. 33, no. 3, pp. 204-213, 2016, in Chinese.

[11] Q. He, He Wang, and W. Wu, "Hysteresis behavior of selfcentering energy dissipation rocking column with different parameters," Journal of Shenyang University, vol. 34, no. 2, pp. 229-238, 2018, in Chinese.

[12] L. Xu, X. Fan, D. Lu et al., "Hysteretic behavior studies of selfcentering energy dissipation bracing system," Steel and Composite Structures, vol. 20, no. 6, pp. 1205-1219, 2016.

[13] L. Xu, X. Fan, C. Dai et al., "Mechanical behavior analysis and experimental study on pre-pressed spring self-centering energy dissipation brace," Journal of Building Structures, vol. 37, no. 9, pp. 142-148, 2016, in Chinese.

[14] L. H. Xu, X. W. Fan, and Z. X. Li, "Cyclic behavior and failure mechanism of self-centering energy dissipation braces with pre-pressed combination disc springs," Earthquake Engineering and Structural Dynamics, vol. 46, no. 7, pp. 10651080, 2017.

[15] Z. Zhou and Y. Chen, "Development and seismic tests of steel dual-core self-centering braces: fiber-reinforced polymer composites as post-tensioning tendons," China Civil Engineering Journal, vol. 45, no. 2, pp. 202-206, 2012, in Chinese.

[16] Z. Zhou, X. T. He, J. Wu et al., "Development of a novel selfcentering buckling-restrained brace with BFRP composite tendons," Steel and Composite Structures, vol. 16, no. 5, pp. 491-506, 2014.
[17] C. Christopoulos, R. Tremblay, H. J. Kim et al., "Self-centering energy dissipative bracing system for the seismic resistance of structures: development and validation," Journal of Structural Engineering, vol. 134, no. 1, pp. 96-107, 2008.

[18] Ministry of Housing and Urban-Rural Construction of the People's Republic of China, Technical Specification for Seismic Energy Dissipation of Buildings (JGJ297-2013), Building Industry Press of China, Beijing, China, 2013.

[19] Ministry of Housing and Urban-Rural Construction of the People's Republic of China, Dampers for Vibration Energy Dissipation of Buildings (JG/T 209-2012), Quality Press of China, Beijing, China, 2014.

[20] S. Liu, Study on Properties of a New Type of Self-Centering Variable Friction Brace, Lanzhou University of Technology, Lanzhou, China, 2010. 